\title{
Editorial: Microbial Biominerals: Toward New Functions and Resource Recovery
}

\author{
Lucian C. Staicu $^{1 *}$, Eric D. van Hullebusch ${ }^{2}$ and Christopher Ackerson ${ }^{3}$ \\ ${ }^{1}$ Faculty of Biology, University of Warsaw, Warsaw, Poland, ${ }^{2}$ Université de Paris, Institut de Physique du Globe de Paris, \\ CNRS, Paris, France, ${ }^{3}$ Chemistry Department, Colorado State University, Fort Collins, CO, United States
}

Keywords: microbial biominerals, biomineralization, metals, environmental depollution, resource recovery

Editorial on the Research Topic

Microbial Biominerals: Towards New Functions and Resource Recovery

Microbes form biominerals via biologically-controlled mineralization (BCM) and biologicallyinduced mineralization (BIM) (Konhauser and Riding, 2012). BCM is commonly an intracellular process, where microbes employ genetic determinants and enzymes to induce mineralization. The end product (the biomineral) of BCM serves a biological function for its host. Some notable examples include magnetotactic bacteria (the magnetite chain helps target microaerophilic environments) and bacteria that biomineralize carbonates (intracellular carbonate contributes to buoyant density) (Uebe and Schüler, 2016; Görgen et al., 2021). Conversely, mineral formation in BIM does not have a regulatory control and the biomineralization product is generally located outside the cell. Numerous minerals are being formed via this process such as $\mathrm{BaSO}_{4}, \mathrm{PbS}$ or iron minerals. BIM-produced biominerals do not often have a clear biological function. For instance, respiratory-sourced biogenic $\mathrm{Se}^{0}$ may contribute to the buoyant density of sludge granules in upflow bioreactors (Staicu and Barton, 2021). However, with the renewed interest in microbial biominerals new biological functions may be acknowledged in the future.

Various industrial effluents are characterized by an abundance of metals/metalloids and anionic complexes present in dissolved and harmful form for aquatic and terrestrial ecosystems. In this context, removing some of these components in the form of stable (bio)minerals is regarded as a sound depollution strategy (Staicu et al., 2021). Because certain bacteria have enzymatic systems with high affinity for certain metals, these can be targeted even when present in complex matrices and stabilized in biominerals (e.g., $\mathrm{Pb}$ in PbS, as per Staicu et al., 2020). Biominerals have high chemical stability often times exceeding greatly their chemical counterparts due to the contribution of their biological matrix (Konhauser and Riding, 2012). Some minerals (e.g., $\mathrm{BaSO}_{4}$ ) are classified as critical raw materials (CRM) due to their scarcity and economical/geostrategic importance. As such, the quest for metals and minerals needed to decarbonize the economy will stimulate the reevaluation of metal-rich wastes in the framework of circular economy (Staicu and Stolz, 2021).

This Research Topic comprises 5 original research articles and presents recent progress in the study of microbial biominerals exploring fundamental and applied aspects. Included are contributions on biogenic $S^{0}$, twisted stalk formation, microbial diversity and biomineralization in metal-polluted mine waters, calcite biomineralization, and the economics of recovering biogenic magnetite. The paper of Cron et al. investigates the role of extracellular polymeric substance (EPS) in the formation and preservation of elemental sulfur, $S^{0}$, biominerals produced by sulfuroxidizing bacteria. Elemental sulfur organomineralization is documented in this paper using an environmental sample (a Sulfurovum-rich biofilm in the Frasassi Cave System, Italy).

Received: 16 October 2021 Accepted: 08 November 2021 Published: 29 November 2021

Citation:

Staicu LC, van Hullebusch ED and Ackerson C (2021) Editorial: Microbial Biominerals: Toward New Functions

and Resource Recovery.

Front. Microbiol. 12:796374.

doi: 10.3389/fmicb.2021.796374 
Iron is essential for microbial metabolism (e.g, chemolithotrophic energy generation, regulatory proteins), however its processing can lead to detrimental biominerals for the host cell. The study by Koeksoy et al. looks into the underlying genetic and physiological mechanisms of twisted stalk formation (unique bacterial extracellular organo-metallic structures containing $\mathrm{Fe}$ (III) oxyhydroxides produced by Fe(II)oxidizing bacteria). The paper presents a candidate gene cluster for the biosynthesis and secretion of the stalk organic matrix that was identified with a trait based analyses of a pan-genome comprising 16 Zetaproteobacteria isolate genomes.

The microbial diversity in metal-polluted mine waters is a key factor in the natural attenuation of industrial pollution. Paganin et al. propose a complex analysis including microbiological, mineralogical and geochemical data to study the indigenous sulfate-reducing bacteria (SRB) involved in metal biomineralization occurring in Iglesiente and Arburese districts (SW Sardinia, Italy). Interestingly, the most abundant genera found in the samples analyses in this study did not belong to the traditional SRB groups (i.e., Rahnella, Acinetobacter) indicative of site-specificity of natural microbial communities. The bioprecipitation process using selected cultures with polluted river water showed high removal of $\mathrm{Zn}$ (>97\%) in the form of biogenic $\mathrm{ZnS}$ with tubular morphology.

An important research area focuses on the difference between biominerals and their non-biological counterparts. Zhao et al. employed a facultative anaerobic bacterium, Enterobacter ludwigii SYB1, to document the hydrochemistry, mineral crystallization, and cell surface characteristics of biomineralization. Their findings identified carbonate anhydrase and ammonia production as major factors influencing the alkalinity and saturation of the closed biosystem forming calcite, monohydrocalcite (MHC), and dypingite (hydrated magnesium carbonate mineral). Circular economy attempts to recover and reuse part of the "waste" products resulted from production cycles and microbes could be used to extract valuable minerals. In this issue, Correa et al. assessed the commercial viability of

\section{REFERENCES}

Görgen, S., Benzerara, K., Skouri-Panet, F., Gugger, M., Chauvat, F., and Cassier-Chauvat, C. (2021). The diversity of molecular mechanisms of carbonate biomineralization by bacteria. Discov. Mater. 1:2. doi: 10.1007/s43939-020-00001-9

Konhauser, K., and Riding, R. (2012). "Bacterial biomineralization" in Fundamentals of Geobiology, eds A. H. Knoll, D. E. Canfield, and K. O. Konhauser (Hoboken, New Jersey: John Wiley and Sons), 105-130.

Staicu, L. C., and Barton, L. L. (2021). Selenium respiration in anaerobic bacteria: does energy generation pay off? J. Inorg. Biochem. 222:111509. doi: 10.1016/j.jinorgbio.2021.111509

Staicu, L. C., and Stolz, J. F. (2021). Microbes vs. metals: Harvest and recycle. FEMS Microbiol. Ecol. 97:fiab056. doi: 10.1093/femsec/fiab056

Staicu, L. C., Wojtowicz, P. J., Bargano, D., Posfai, M., Molnar, Z., Ruiz-Agudo, E., et al. (2021). Bioremediation of a polymetallic, arsenic-dominated reverse osmosis reject stream. Lett. Appl. Microbiol. (2021). doi: 10.1111/lam.13578 [Epubh ahead of print].

Staicu, L. C., Wojtowicz, P. J., Posfai, M., Pekker, P., Gorecki, A., Jordan, F. L., et al. (2020). PbS biomineralization using cysteine: Bacillus cereus and the sulfur rush. FEMS Microbiol. Ecol. 96:fiaa151. doi: 10.1093/femsec/fiaa151 industrial production of magnetotactic bacteria (MTB)-derived nanomagnets. Biogenic magnetite is considered to possess superior characteristics and to entail a cleaner production in relation to synthetic nanoparticles, therefore the bioproduction costs are justifiably higher than chemical manufacturing.

Microbial biominerals are key components of the natural biogeochemical cycles of metals, but are also important in anthropogenic settings (industrial infrastructure, wastewater treatment) and industrial-contaminated sites. Their formation is often considered beneficial in terms of environmental depollution. Some future directions of research involving microbial biominerals should focus on (i) elucidation of their unknown biological functions with relevance for fundamental and applied knowledge, (ii) their recovery in the framework of the circular economy paradigm shift, and (iii) decontamination of ever-increasing sites affected by past and contemporary industrial activities.

\section{AUTHOR CONTRIBUTIONS}

All authors listed have made a substantial, direct, and intellectual contribution to the work and approved it for publication.

\section{FUNDING}

LS acknowledges National Science Centre (NCN), Grant No. 2017/26/D/NZ1/00408. EH acknowledges H2020 ERA-MIN 2 funding for the BaCLEM project (Bio-assisted Closed loop recycling of E-Mobility Metals from waste PCBs and Li-Ion Batteries). CA acknowledges grant NIH R01 GM137139.

\section{ACKNOWLEDGMENTS}

We thank the Frontiers in Microbiology editorial staff, especially Barbora Miklasová, for the initial invitation and professional support throughout. We also thank all the reviewers involved in this special issue for their insightful comments and suggestions.

Uebe, R., and Schüler, D. (2016). Magnetosome biogenesis in magnetotactic bacteria. Nat. Rev. Microbiol. 14, 621-637. doi: 10.1038/nrmicro. 2016.99

Conflict of Interest: The authors declare that the research was conducted in the absence of any commercial or financial relationships that could be construed as a potential conflict of interest.

Publisher's Note: All claims expressed in this article are solely those of the authors and do not necessarily represent those of their affiliated organizations, or those of the publisher, the editors and the reviewers. Any product that may be evaluated in this article, or claim that may be made by its manufacturer, is not guaranteed or endorsed by the publisher.

Copyright (c) 2021 Staicu, van Hullebusch and Ackerson. This is an open-access article distributed under the terms of the Creative Commons Attribution License (CC $B Y)$. The use, distribution or reproduction in other forums is permitted, provided the original author(s) and the copyright owner(s) are credited and that the original publication in this journal is cited, in accordance with accepted academic practice. No use, distribution or reproduction is permitted which does not comply with these terms. 